\title{
Revizyon kalça cerrahisi: cerrahi yaklaşımlar
}

\author{
Revision hip surgery: surgical approaches
}

\author{
Alican Barış ${ }^{1}$, Yusuf Öztürkmen² \\ 'Sağlık Bilimleri Üniversitesi, Haydarpaşa Numune Eğitim ve Araştırma Hastanesi Ortopedi ve Travmatoloji Kliniği, İstanbul \\ ${ }^{2}$ Sağlık Bilimleri Üniversitesi, İstanbul Eğitim ve Araştırma Hastanesi Ortopedi ve Travmatoloji Kliniği, İstanbul
}

Total kalça artroplastisi (TKA) ameliyatı; hastaların fonksiyonel durumlarında önemli iyileşmeler sağlayan, başarı oranı yüksek cerrahi bir prosedürdür. Genç hastalarda dahi artan TKA sayısı, bu işlemin revizyon sayılarında da önemli bir artışa neden olmaktadır. Total kalça artroplastisi revizyon ameliyatının başarısı büyük ölçüde komponentler çıkarıldıktan sonra kalan kemiğin kalitesine, hacmine ve şekline bağlıdır. Katı bir şekilde sabitlenmiş, çimentolu veya çimentosuz TKA komponentlerinin minimum kemik kaybı ile çıkarılması elzemdir. Ayrıca bu işlemler esnasında kemik dokuya yapısal bir zarar verilmemesi gerekmektedir. Bu açıdan düşünüldüğünde, TKA revizyon cerrahisinde komponentlerin çıkarılması teknik olarak zor ve zaman alıcı olabilmektedir. Bu işlemler için ameliyat öncesi iyi bir planlama gerekir. Çıkarılacak komponentler önceden belirlenmeli ve buna göre gerekli tüm aletler (yüksek hızlı oyucular, femoral stem çıkarıcıları, polietilen insert "ara parça" çıkarıcıları, kap çıkarıcıları, tornavidalar ve modüler baş/boyun ayırma aygıtları vb.) hazır bulundurulmalıdır. Gevşek komponentlerin çoğu kolayca çıkarılabiliyorken iyi sabitlenmiş ve çimentolu komponentlerin çıkarılması için çeşitli teknikler tarif edilmiştir. Bu tekniklere bağlı olarak seçilecek cerrahi yaklaşım da farklılık gösterir. Seçilecek yaklaşım olabildiğince güvenli, basit ve anatomik olmalıdır. Kalça eklemine cerrahi yaklaşım, eklem kapsülünün anatomisine göre, anterior, lateral veya posterior olarak sınıflandırılmaktadır. Bu makalede revizyon kalça cerrahisinde en sık kullanılan yaklaşımlar ve bu yaklaşımlar esnasında komponentlerin çıkarılma teknikleri anlatılmaktadır.

Anahtar sözcükler: cerrahi yaklaşım; revizyon kalça artroplastisi; komponent çıkarma tekniği

\section{CERRAHI ÖNCESI PLANLAMA VE HAZIRLIK}

Revizyon kalça artroplastisi cerrahisinde ameliyat öncesi planlama, sürecin önemli aşamalarından biridir. Bu aşamada ayrıntılı öykü alınmalı ve iyi bir fizik muayene yapılmalıdır. Fizik muayenede; önceki cilt insizyonları, yürüyüş paternleri, kas fonksiyonu, bacak uzunluk uyumsuzluğu ve nörolojik durum değerlendirmelidir.
Total hip arthroplasty (THA) is a surgical procedure with a high success rate of improving the functional status of the patients. The number of THA is increasing even among young patients, and this issue has also an important impact on the increase of total hip arthroplasty revisions. Success of revision THA is associated mostly with the quality, volume, and shape of the rest bone after removal of the components. Removal of well-integrated cemented or cementless components of total hip prosthesis must be performed with a minimum bone loss. Moreover, the bony anatomic structure should also not be damaged during this procedure. Therefore, removal of components in revision hip arthroplasty may be technically difficult, and time-consuming. Appropriate preoperative planning is mandatory for these procedures. Instruments for removing components should be determined and all required equipment (high-speed drills and metal cutters, long curved, flexible and rigid osteotomes, femoral stem extractors, polyethylene insert extractors, cup extractors, screw drivers and devices to separate modular head/neck junctions etc.) should be ready before the operation. Most of the loose components may be easily extracted but several techniques are defined to remove well-fixed cemented and cementless components. Depending on these techniques, the surgical approach to be chosen also differs. The approach to be chosen should be as safe, simple, and anatomical as possible. The surgical approach to the hip joint is classified as anterior, lateral, or posterior according to the anatomy of the joint capsule. This article describes the most commonly used approaches in revision hip surgery, and the techniques for removing components during these approaches.

Key words: surgical approach; revision hip arthroplasty; component removal technique

Şikâyet ve şikâyetin sebepleri irdelenmeli, birincil operasyonla ilgili yaklaşım ve komplikasyonlar dikkatlice incelenmelidir. Tam kan sayımı, eritrosit sedimentasyon hızı ve C-reaktif protein (CRP) değerlerinin belirlenmesi ile, enfeksiyon ekarte edilmelidir. Anormal kan değerleri veya önceki sepsis öyküsü durumunda, kalça aspiratı kültürü düşünülmelidir. ${ }^{[1-3]}$ Cerrahi öncesinde,

İletişim / Contact: Prof. Dr. Yusuf Öztürkmen • E-posta / E-mail: yozturkmen@gmail.com

ORCID iD: Alican Barış, 0000-0001-6031-6777 • Yusuf Öztürkmen, 0000-0002-2199-2411

Geliş / Received: 16 Eylül 2021 • Kabul / Accepted: 3 Ekim 2021 
implant etiketlerinden veya ameliyat notlarından komponentlerin üreticisi belirlenmelidir. Gerekli durumlarda implant çeşidinin tespiti için radyografilerden de yararlanılabilir. Pelvis anteroposterior (AP) ve lateral kalça radyografileri; asetabular komponentin yerleşimini, kemik kaybının derecesini, ilişkili bir kırığı veya pelvik ayrışmayı tespit edebilir. Ayrıca gerekli durumlarda Judet radyografik görüntülerine de başvurulabilir. ${ }^{[4]}$ Femoral komponentin gevşemesini değerlendirmek için de ayrıntılı bir çalışmanın yapılması gerekir. Ameliyat öncesi planlama sırasında, önceki prosedürlerin tüm kayıtları ve radyografiler gözden geçirilmelidir. Seri radyografiler, implant stabilitesi hakkında önemli veriler sağlayabilir. Tüm femuru içerecek şekilde AP ve lateral femur grafileri de çekilmelidir. ${ }^{[1-3]}$

Bilgisayarlı tomografi (BT), implantın güvenli bir şekilde çıkarılması ve nihai rekonstrüksiyon açısından mevcut kemik stoğu hakkında önemli veriler sağlayabilir. Kemik stoğu değerlendirilirken; süngerimsi kemik kaybı miktarı ve çimento mantosu kalınlığı veya perforasyona duyarlı olabilecek ince korteks alanları dikkate alınmalıdır. ${ }^{[1-3]}$ Asetabular komponentin pelvise aşırı migrasyonu durumlarında, iliak damarların migrasyon yapan komponent ile yakınlığını belirlemek için pelvis BT anjiyografisi yapılabilir. Bu tarz migre (yer değiştirmiş) ve kompleks asetabular komponentlerin çıkarılması esnasında, kalp damar cerrahisi ve/veya genel cerrahi bölümlerinden de destek alınabilir. ${ }^{[4]}$

Nükleer kemik sintigrafisi nadiren gereklidir. Ancak radyografik gevşeme belirtileri olmayan hastalarda komponent stabilitesini belirlemeye yardımcı olabilir. ${ }^{[1-3]}$

Asetabular komponentin revizyonu, komponent pozisyonundaki gevşeme ve değişiklik radyografik olarak tanımlandığında veya ameliyat sırasında manipülasyon ile komponentin stabilitesi kaybolduğunda endikedir. Kronik enfeksiyon, osteoliz, kalça instabilitesi (uygun olmayan komponent yerleşimi veya kısıtlayıcı protez gereksinimi) durumlarında, sağlam bir şekilde sabitlenmiş olsa dahi, asetabular komponentin çıkarılması gerekir. Bazı durumlarda sorun sadece polietilen insertte olabilir. Aşırı aşınmış polietilen insert durumun$\mathrm{da}$; asetabular komponent pelvise sağlam oturmuş, konumu anatomik ve polietilen insert ile olan kilitleme mekanizması düzgün işliyorsa, bu durumda asetabular komponentin sadece polietilen insert kısmı değiştirilebilir. ${ }^{[5-7]}$ Femoral komponentin revizyonunu gerektirecek en önemli unsur ise implantın stabilitesidir. Ağrılı ve mekanik olarak stabil olmayan femoral komponent, çıkarılmayı gerektirir. Ameliyat öncesi klinik muayene ile kalça veya uyluk ağrısının başlangıcının belirlenmesi, komponentin gevşek olup olmadığını anlamaya yardımcı olabilir. ${ }^{[1,2,8,9]}$
Revizyon ameliyatı esnasında gerekli olabilecek tüm alet ve ekipman (metal kesme özelliği olan yüksek devirli kesici ve oyucular, gigle testeresi, osteotomlar, serklaj kablolar, üniversal femoral stem çıkarıcıları, küretler, tutucu kancalar vb.) hazır bulundurulmalıdır. ${ }^{[2,3,9]}$

Cerrahi yaklaşım, önceki operasyona ve cerrahın beceri/tecrübesine göre belirlenmelidir. Komponentin çıkarılması için yeterli açılım sağlayacaksa, önceki cilt insizyonları kullanılabilir. ${ }^{[2,3,9]}$ Cerrahi insizyonlar, komponentlerin rahatlıkla çıkarılabileceği genişlikte olmalıdır. Posterior yaklaşım, asetabuluma optimum erişime izin verdiğinden ve trokanterik osteotomi gibi diğer rekonstrüksiyon seçenekleri için genişletilebilir olduğundan dolayı daha çok önerilmektedir. ${ }^{[10-12]}$ Ancak revizyon için direkt lateral, anterior ve anterolateral yaklaşımlar da tanımlanmıştır. ${ }^{[2,3,9]}$

\section{CERRAHI YAKLAŞIM YÖNTEMLERI}

\section{Anterior Yaklaşım}

Hızlı yara iyileşmesi ve düşük çıkık oranları sayesinde, revizyon kalça cerrahisinde anteriora yaklaşıma olan ilgi artmaktadır. ${ }^{[13-15]}$ Smith-Petersen yaklaşımı ve Robert Judet tarafindan modifiye edilen Hueter yaklaşımı, en bilinen örneklerdir. ${ }^{[16]}$

Cilt insizyonu anterior superior iliak spinedan (ASIS) başlar. ${ }^{[16]}$ Cilt ve cilt altı geçildikten sonra, tensör fasyasının önünden girilir. Yüzeysel interval, tensör fasya kası (superior gluteal sinir) ve sartorius kası (femoral sinir) arasında; derin interval ise, tensör veya gluteus minimus kası (superior gluteal sinir) ile rektus femoris (femoral sinir) arasındadır. Başlangıç insizyonu, tensör kasının iliak krest üzerinden subperiostal disseksiyonu ile, 2-3 cm kadar proksimale uzatılabilir. Orijinal insizyonun distale doğru uzatılması ile, standart lateral yaklaşıma dönüştürülebilir. Bu esnada, vastus lateralis kasının anteriora mobilizasyonu ile femoral görüş alanı artırılabilir. Alternatif olarak, femuru doğrudan ortaya çıkarmak için ikinci bir lateral cilt kesisi de yapılabilir. ${ }^{[13,14,16]}$ Anterior yaklaşım, kaslar ve sinirler arasında bir aralıktan geçiş sağladığı için, kasları korumanın bir yolu olarak kullanılmaktadır. Fakat bu yaklaşım, revizyon kalça cerrahisinde posterior kolon ve posterior duvardaki kemik defeklerine ulaşımı kısıtlamakta, posterior kolon stabilizasyonunun sağlanmasını zorlaştırmaktadır. ${ }^{[17]}$

\section{Direkt Lateral Yaklaşım}

Direkt lateral yaklaşım, kalça eklemi cerrahisinin birçok çeşidinde yaygın olarak kullanılan çok yönlü bir yaklaşımdır. İlk olarak Innsbruck Üniversitesi'nden Bauer ve ark. tarafindan tanımlanmış ve 1979'da kalça eklemine transgluteal yaklaşım olarak rapor 
edilmiştir. ${ }^{[18]} 1982$ 'de Wrightington Hastanesi'nden Kevin Hardinge tarafindan Sir John Charnley'in trokanterik osteotomi kullanan total kalça artroplastisi (TKA) yaklaşımına bir alternatif olarak popüler hale getirilmiştir ve 'Hardinge yaklaşımı' olarak da bilinmektedir. ${ }^{[19]}$ Direkt lateral yaklaşımın modifikasyonları; trokanterik flep ile anterior olarak alınan gluteus medius ve vastus kas dokusunun miktarına, sadece yumuşak doku alınıp alınmamasına, yumuşak dokuya kemik parçası veya daha önemli bir kemik eklentisinin dâhil edilip edilmemesine göre tanımlanmıştır. [20]

İnsizyon, büyük trokanter üzerinden başlar. ${ }^{[17]}$ Büyük trokanterin önünden devamlı uzunlamasına bir giriş ile, vastus-gluteal muskulotendinöz flep aracılığıyla kalça eklemi ön kapsülüne ulaşılır. Kasların büyük trokanter üzerindeki tendinöz insersiyosu veya periostun ince olduğu durumlarda birçok cerrah, büyük trokanterin ön kemik çıkıntısını yumuşak dokuya dâhil ederek flebi kalınlaştırmaktadır. ${ }^{[20]}$ Derin insizyon, gluteus medius lifleri arasından proksimale doğru, femur anterolateralinden de distale doğru uzatılabilir. ${ }^{[17,21]}$

Direkt lateral yaklaşım, komplike olmayan primer TKA'da yaygın olarak kullanılmaktadır. Özellikle hafif ile orta derecede asetabular displazi ve aşırı femoral anteversiyonu olan kalça eklemi rekonstrüksiyonunda önerilmektedir. Bu durumda, femur başı sıklıkla öne doğru subluksedir; hafif fleksiyon, dış rotasyon ve adduksiyon ile kolayca yerinden çıkarılabilir. Bu yaklaşım aynı zamanda, pelvik halka, asetabular kolon veya femur şaftın geniş açılımını gerektirmeyen, daha basit revizyon TKA'da (asetabular liner değişimi gibi...) da kullanılabilir. ${ }^{[17,21]}$

Doğrudan lateral yaklaşımın kullanımını son derece zorlaştıran, kalça çevresinde önceki insizyonların (aşırı posterior insizyon gibi...) varlığında ve asetabular kolon ya da femur şaftı için geniş açılım gerektiren durumlarda, bu yaklaşım önerilmemektedir. ${ }^{[22]}$

Posterior yaklaşımın aksine, bu yaklaşımda insizyon proksimale çok uzatılırsa, superior gluteal sinirin yaralanma olasılı̆̆ı vardır. Ayrıca ameliyat sonrası heterotopik ossifikasyon, abduktor güçsüzlük ve topallama sık görülmektedir. ${ }^{[17]}$

\section{Anterolateral Yaklaşım}

Watson-Jones yaklaşımı olarak da bilinir. Cilt insizyonu, lateralde büyük trokanter üzerinde ve bacak eksenine paralel olarak yapılır; proksimal ve distal yönlerde simetrik olarak devam ettirilir. Subkutanöz katman, kranial ve kaudale doğru altındaki fasya latadan künt olarak disseke edilir; tensör fasya lata ve gluteus medius kası arasındaki intermusküler septumdan girilir. Primer kalça protezi cerrahisinde iyi bir yaklaşım olsa da, asetabulum için yeterli görüş sağlamadığı için, revizyon kalça cerrahisinde sınırlı kullanılmaktadır. ${ }^{[17,23]}$

\section{Posterolateral Yaklaşım}

Kalça posterolateral yaklaşımı primer ve revizyon total TKA için sıkça kullanılmaktadır. On dokuzuncu yüzyıldan itibaren birçok cerrah tarafından bu yaklaşımın küçük modifikasyonları tanımlanmıştır. Daha az invaziv cerrahi ile, geniş açılım ve iyi bir görüş sağlanmaktadır. Birçok cerrah, asetabulum arka duvarına, pelvis arka kolonuna ve gerektiğinde femurun tamamına erişim sağladığı için, revizyon TKA'da bu yaklaşımı tercih etmektedir. Trokanterik osteotomi, periprostetik kırıkların tespiti ve revizyon TKA'da pelvik rekonstrüksiyon, bu yaklaşımla güvenle yapılabilmektedir. Ön kolon kırıkları, kalçaya önceki anterior yaklaşım, çıkık açısından yüksek risk altındaki hastalar (nörolojik bozukluk, Parkinson hastalığı, uyumsuzluk, demans gibi...) bu yaklaşımın rölatif kontrendikasyonları olarak bildirilmektedir. ${ }^{[24-27]}$

Hasta lateral dekubit pozisyonunda iken, standart posterolateral yaklaşım yapılır. Pubis, anterior ilium ve lumbosakral omurgayı sabitlemek için, ticari kalça pozisyonlayıcıları, masa kıskaçları veya peg panoları kullanılır. ${ }^{[25,26]}$ Cerrahi insizyon, prosedüre ve gerekli açılıma göre değişir; tipik olarak, femurun arka üçte biri boyunca, kalça büyük trokanter seviyesinde fleksiyonda iken yapılır; femur hizasında distale doğru uzatılır. Posterior kolon ve pelvis görüşü sağlamak için, insizyon PSiS'ye doğru proksimale genişletilebilir. Femurun tamamını ortaya çıkarmak için de, insizyon uyluk boyunca distale uzatılarak diz seviyesinde öne doğru kıvrılabilir. Kalça çevresindeki deride kanlanma iyi olduğu için kalça çevresindeki yara nekrozu nadir görülür. Yine de, mümkünse önceki cilt kesileri kullanılmalıdır. Yeni bir kesi yapılacaksa, en az $8 \mathrm{~cm}$ 'lik geniş cilt köprüleri korunmalıdır. Cilt ve cilt altı kesisi sonrası, disseksiyona proksimalde gluteus maksimusun üzerini örten fasya ve distalde iliotibial bant kesileri ile devam edilebilir. Revizyon cerrahisi sırasında anatomik katmanları tanımlamak genellikle zordur. Potansiyel ölü boşluk oluşmasına yol açan çoklu disseksiyon düzlemleri oluşturmamak için gerekli özen gösterilmelidir. Gluteus maksimus kası lifleri arasından künt disseksiyon ile proksimal açılım genişletilir. Revizyon cerrahisinde, gluteus maksimus tendonu sıklıkla posterior femurun gluteal tuberositastaki yerleşiminden serbestleştirilir. Kapama sırasında, onarım için femur üzerinde yeteri kadar yumuşak doku bırakılır. Daha önceki cerrahide piriformis ve diğer kısa dış rotator kasları onarılmış ise revizyon 
TKA'da bu kaslar seçilebilir. Ancak, çevreleyen skar dokusu genellikle bu kasların ve tendonlarının açıkça tanımlanmasını güçleştirir. Revizyon cerrahisinde, bu doku düzlemi tipik olarak alttaki kapsül ile tek katman halinde kaldırılır. ${ }^{[24-27]}$

Posterolateral açıım tamamlandığında, hem asetabulum hem de femur komponenti açısından iyi bir görüş sağlanmış olur. Revizyon TKA'da, uygun cerrahi teknik uygulandığında komplikasyon oranları minimalize olmaktadır. ${ }^{[24]}$ Yine de, posterolateral yaklaşımla gerçekleştirilen TKA'ların \%20'sinden fazlasında heterotopik ossifikasyon meydana gelmektedir. $\mathrm{Bu}$ heterotopik ossifikasyon oranı önemlidir; ancak yine de, anterolateral veya transtrokanterik yaklaşımın kullanıldığı olgulardaki oranlardan daha düşüktür. ${ }^{[28]}$ Bu yaklaşımla, revizyon TKA'da siyatik sinir felci oranı \%7,6'ya kadar çıkabilmektedir. Bu oran, primer TKA'da gözlenen $\% 0,25$ 'in altındaki orandan çok daha yüksektir. Siyatik sinir genellikle fibröz dokular arasında sıkışır; dikkatli palpasyon ve nöroliz ile sinirin konumu belirlenip korunmalıdır. ${ }^{[29]}$ Primer ve revizyon TKA cerrahisinde sinir monitörizasyonunun sinirin koruması yönünde yararının olmadığı bildirilmektedir. ${ }^{[30]}$ Ancak, asetabular rekonstrüksiyon işlemi esnasında femurun aşırı retraksiyonunun sinir iletim anormalliğine neden olduğu gösterilmiştir. Şiddetli retraksiyondan önce yumuşak doku gevşetilmesi gerektiği bildirilmektedir. ${ }^{[31,32]}$ Posterolateral yaklaşımın en önemli dezavantajı, TKA sonrası çıkık oranıdır. İyimser tahminlerde bile, revizyon TKA sonrası dislokasyon oranları \%7 ile \%10 arasında değişmektedir. Obezite (body mass index, >35), abduktor zayıflık, nöromusküler bozukluk ve fleksiyon, iç rotasyon veya adduksiyon kontraktürü durumlarında, revizyon TKA sonrası çıkık oranlarında artma görülmektedir. ${ }^{[33]}$ Çıkığın, cerrahi yaklaşımla ilgili değil de, revizyonun bir komponenti olduğu yönünde görüşler bildirilmektedir. Ancak iyi bir kapsül onarımının primer ve revizyon TKA'da çıkık oranını azalttığı gösterilmiştir. Ayrıca femur başı boyutunun artırılmasının, revizyon TKA'dan sonra stabiliteyi artırdığı ve çıkık oranlarını azalttığı savunulmaktadır. ${ }^{[34-36]}$

\section{Posterior Yaklaşım}

Posterior yaklaşım, total kalça protezi için muhtemelen en sık kullanılan yaklaşımdır. Moore veya Southern yaklaşımı olarak adlandırılan klasik posterior yaklaşım, posterior kalça ve büyük trokanter üzerinden başlar ve femurun yarısına kadar devam eder. Revizyon cerrahisinde (kalça, asetabulum ve femurun daha iyi görülmesi açısından) insizyon genellikle proksimale ve distale genişletilebilir. Fasya lata geçilip gluteus maksimus kası lifleri aralandığında, kısa dış rotator kasları açığa çıkar. Kısa dış rotator tendonları ve kapsülün oluşturduğu flep geriye yatırılarak, hem siyatik sinir korunur hem de protez daha da açığa çıkartılır. Abduktor kasların gerginliğini korumak için, ameliyat bittiğinde bu flep tekrar büyük trokantere sabitlenir. ${ }^{[17,24]}$

\section{Genişletilmiş Trokanterik Osteotomi}

Revizyon kalça cerrahisi zorlu bir süreç olduğu için standart yaklaşım dışında farklı yaklaşımlara ihtiyaç duyulabilmektedir. Paprosky tarafından tanımlanmış ve Wagner'in modifiye ettiği 'Geniş̧letilmiş Trokanterik Osteotomi' (GTO) tekniği revizyon kalça cerrahisinde sıkça kullanılmaktadır. ${ }^{[37,38]}$ Bu osteotomi posterior yaklaşımla tanımlanmıştır; ancak anterolateral yaklaşımla da yapılabilmektedir. Sıkı bağlanmış distal kemik-çimento ara yüzü varlığında, varus/ valgusta femoral deformite ya da femoral kanalın düz bir şekilde oyulmasını engelleyen diğer deformitelerin olduğu hallerde, çimentosuz femoral stemlerde kemik ingrowth görüldügüunde veya büyük trokanter hasar riski olan migre olmuş (yer değiştirmiş) femoral stem varsa, GTO önerilmektedir. Osteotomi, kalça lukse edilmeden önce, kalça lukse edilip ancak femoral komponentin çıkarılmasından önce veya kalça luksasyonu sonrası femoral komponentin çıkarıldıktan sonra yapılabilir. ${ }^{[37-39]}$

\section{Çimentolu asetabular komponentin çıkartılması}

İyi sabitlenmiş ve eski çimentolu asetabular komponentlerin çıkarılması, uğraştırıcı bir prosedürdür. Bunun için birçok teknik tarif edilmiştir; bu tekniklerin çoğunda temel prensipler benzerdir. Genel olarak, önce komponentin çimentodan ayrılması, ardından kemik çimentonun temizlenmesi mantığına dayanır. Önce kavisli osteotomlar yardımı ile komponent-çimento ara yüzüne girilerek, komponent kemik mantodan gevşetilir; bu gevşetme işlemi çepeçevre yapılır. Daha sonra bir tutucu yardımı ile nazikçe, bir yandan diğer yana doğru ve döndürme biçiminde hareketler ile komponentin polietilen kısmı çıkarılır. Asetabular kemik hasarı ve kırık riski açısından, kaldırma ve çekme yapan aletlerin kullanımı önerilmez. Çimento mantosunu kemikten ayırmak için yine çeşitli osteotomlar kullanılır. Bu esnada kemik stoğu olabildiğince korunmalıdır. Gerekli durumlarda, çimento manto parçalara ayrılarak çıkarılabilir. Yüksek devirli ince kesici ve oyucuların kullanılması, kemik kaybı ve hasarı olasılığını azaltarak, kemik-çimento ara yüzeyinin açılmasını sağlar. Polietilen kabın kemik çimento içinde asetabuluma gömülü olduğu bazı durumlarda asetabular raspalar kullanışlı olabilir. Polietilen kap raspalanarak inceltilip esnetilir ve daha sonra osteotomlar yardımı ile çıkarılır. ${ }^{[40-42]}$ 

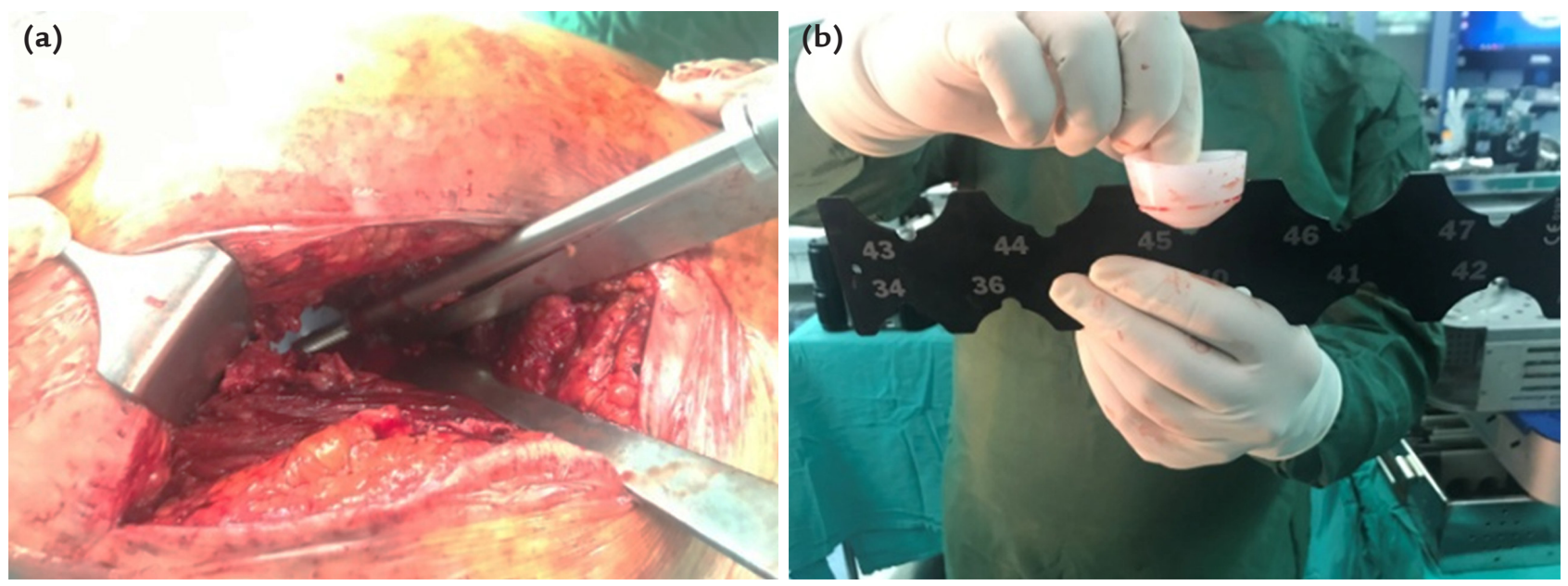

Şekil 1. a, b. Polietilen insertin vidalama tekniği (a) ile çıkarılması (b).

\section{Çimentosuz asetabular komponentin çıkartılması}

Çimentosuz asetabular komponentlerde önce polietilen insert çıkarılmalıdır. Polietilen insert, farklı kilitleme mekanizmaları ile asetabular komponente kilitlenmiş olabilir. Bunu ayırmak için, üretici firmaya bağlı farklı tekniklere göre farklı spesifik aletlere ihtiyaç duyulabilir. Eğer bu spesifik aletlere ulaşılamıyorsa veya kilitleme mekanizması bozulmuş ise alternatif yöntemlere başvurulabilir. Polietilen insertin kenarları metal kabın dışına taşıyorsa, bir osteotom yardımı ile çıkarılabilir. Başka bir yöntem de, polietilen insertin ortasından bir drill ile delik açılmasıdır. Bu deliğin içinden $6,5 \mathrm{~mm}$ 'lik asetabular vida ilerletilir; vida ilerledikçe, polietilen insert metal kaptan dışarı doğru itilir (Şekil 1). ${ }^{\text {7] }}$

Asetabular komponentin metal kısmının uzaklaştırılması esnasında, uygun cerrahi alet ve tekniklerin dikkatli kullanımı ile kemik kaybı miktarı en aza indirilebilir. Eğer asetabular komponentin metal kısmı vida ile sabitlenmiş ise doğru tornavida ameliyat esnasında hazır bulundurulmalıdır. Vida uçları yalama olmuşsa, vida başlarını kesmek için yüksek devirli oyucu ve kesicilere ihtiyaç duyulabilir. Geleneksel osteotomların kullanılması aşırı kemik kaybına neden olabilir. İmplantın çıkarılması sırasında kemik kaybı miktarını en aza indirmek için çok sayıda teknik geliştirilmiş̧tir. Komponentin superolateral kısmının hizasında kemikte 3-4 mm'lik bir delik açılarak, kap açılı bir alet ile implant-kemik ara yüzeyinden dışarı doğru itilebilir. Ince bıçaklı bir testere yardımı ile ulaşılabilen bölgelerde kemik-implant ayırımı yapılabilir. Testere düzgün ve dikkatli kullanılmazsa kemik stoğunda kayba neden olabilir. Yaygın olarak baş vurulmayan bir teknik de kabın çıkarılması zor olduğu takdirde yüksek devirli metal kesecilerin kullanılmasıdır. Metal bileşen birkaç parçaya ayırdıktan sonra bu parçalar tek tek çıkarılabilir. Metal debris oluşumu, uzayan ameliyat süresi, cerrahi ekipmanın hasar görmesi ve kemik doku hasarı, bu yöntemin dezavantajları olarak bildirilmektedir. ${ }^{[4,43,44]}$

İyi sabitlenmiş bir asetabular komponentin çıkarılması için en yaygın kullanılan tekniklerden biri de, komponentin çapına özel ve ticari olarak temin edilebilen kavisli bıçağa sahip çıkarıcılardır (Şekil 2). ${ }^{[45]}$

$\mathrm{Bu}$ aletleri yerleştirmeden önce, asetabular komponentin çevresindeki tüm yumuşak doku ve kallus komponent ve kemik ara yüzünü görmek için eksize edilmelidir. Daha sonra asetabular komponent, tüm komponent yüzeyi boyunca komponentin çapına uygun çıkarıcı yerleştirilerek, minimal kemik stoğu kaybı ile çıkarılabilir (Şekil 3). ${ }^{[45]}$

\section{Çimentolu femoral komponentin çıkartılması}

Çimentolu femoral stem çıkarıcısı ile proksimale doğru bir kuvvet uygulandığında, çimento mantosundan genellikle ayrılabilir. Çıkarma işlemi sırasında büyük trokanter kırı̆̆ını önlemek için, komponentin proksimal kısmının lateralindeki çimento ve büyük trokanterin medial kısmındaki kemiksel yapılar önceden eksize edilmelidir. Eğer yakalıklı stem kullanılmışsa proksimaldeki tüm çimento çıkarılmalıdır. Stem çıkarıldıktan sonra distalde kalan çimento da uzaklaştırılmalıdır. Bunun için kullanılan teknik, cerrahın deneyimine bağlıdır. Genişletilmiş trokanterik osteotomi (GTO) tekniği kullanılmayan yaklaşımlarda, çimento medüller kanaldan üç aşamada dikkatli bir şekilde temizlenebilir: Önce küçük trokanterin üstündeki metafiz çimentosu, sonra küçük trokanterin 

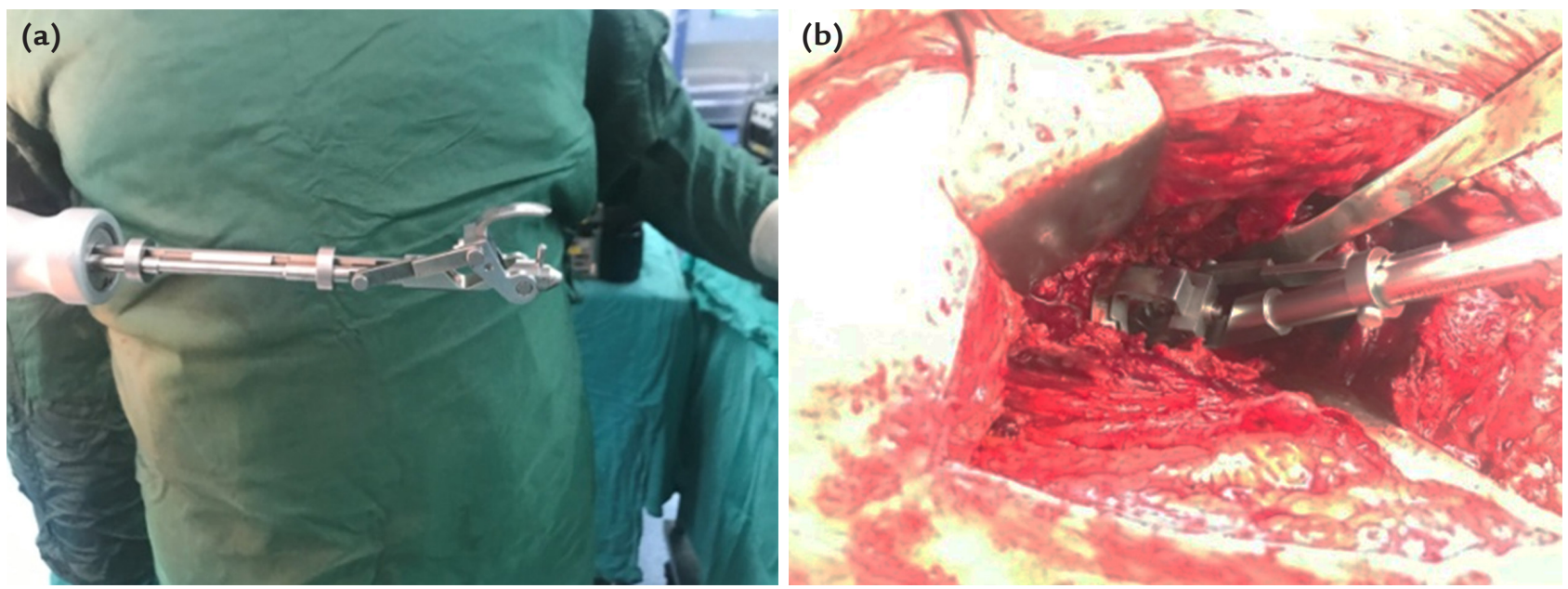

Şekil 2. a, b. Asetabular komponent çıkarılması için tasarlanmış çıkarıcı (a) ve uygulanması (b).
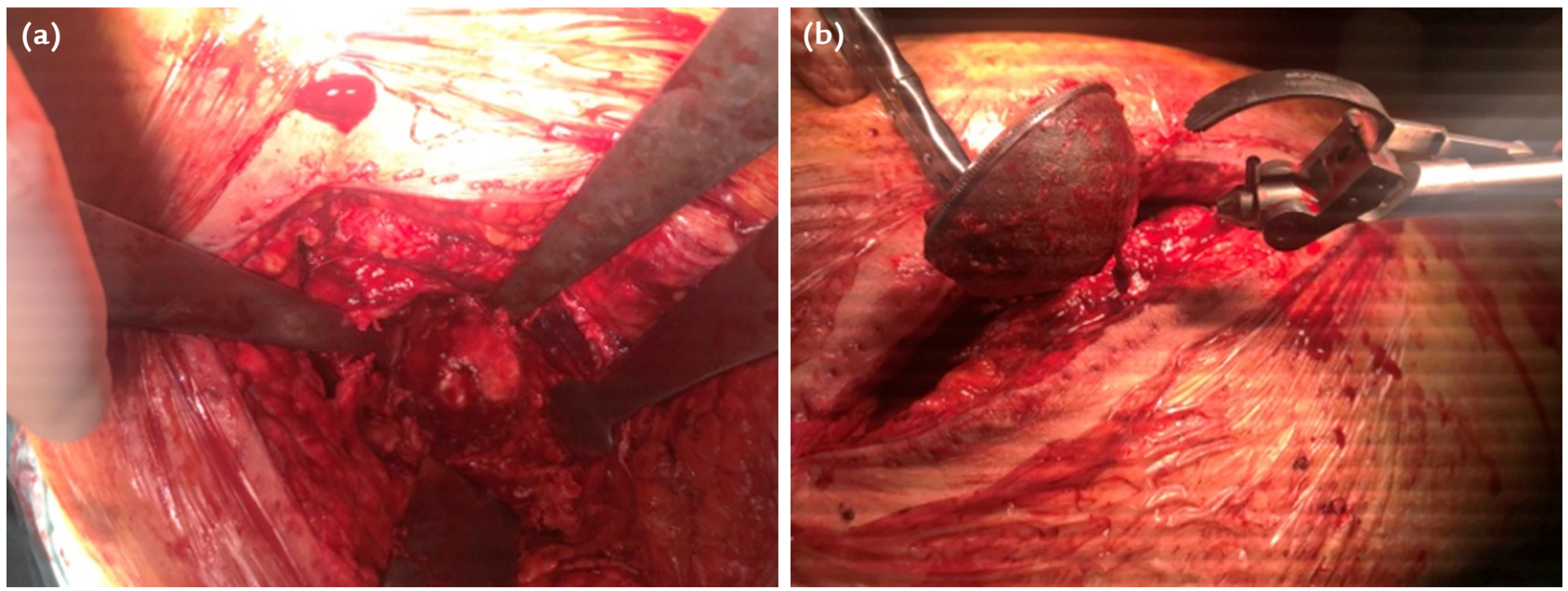

Şekil 3. a, b. Minimal kemik kaybı ile asetabular komponentin çıkarılması.

altındaki diyafız çimentosu temizlenir; ardından distal çimento tıkacı çıkarılır. Metafiz ve diyafiz bölgelerindeki kemik-çimento ara yüzünü zayıflatmak ve bölmek için, yüksek devirli oyucular ve farklı şekillerdeki osteotomlar kullanılabilir. Çimentonun fikse ve kalın bir tabakaya sahip olduğu durumlarda, çimentoyu bir oluk ile ayırmaya yönelik girişimler femur kırığına neden olabilir. Bundan dolayı, çimentonun güvenli bir şekilde ayrılmasını sağlayan uzunlamasına oluklar yapılmalıdır. Distal çimento tıkacının çıkarılması da hassasiyet gerektiren bir işlemdir. Skopi kontrolü altında distal çimento tıkacını delmek için $4,5 \mathrm{~mm}$ veya 6 mm'lik drill kullanılabilir. Ardından, ince bir kanca küret drill uygulanan bölgeden ilerletilerek tıkaç geri çekilebilir. Çalışmalarda, çimento-çimento arasındaki tutulumun çimento-kemik arasındaki tutulumdan daha kuvvetli olduğu gösterilmiştir. Bundan yararlanarak, çimento mantosuna yeni çimento doldurmayı öneren çalışmalar vardır. ${ }^{[46]}$ Yeni çimentoya stem yerleştirilerek tüm komponent çıkarılabilir. Ayrıca, çimentonun çıkarılması için ultrasonik alternatif yöntemler de bildirilmiştir. ${ }^{[46-48]}$

\section{Çimentosuz femoral komponentin çıkartılması}

Çimentosuz femoral komponentin çıkarılma şekli, stemin gevşek veya iyi sabitlenmiş olup olmamasına, bunun yanı sıra poröz kaplı olup olmamasına göre de değişir. Stem gevşek ise, çıkartıcı sistem ile kolayca çıkartılabilir (Şekil 4). ${ }^{4,49]}$

Ancak komponent iyi sabitlenmişse, çıkarmak için özel yöntemler denenebilir; öncelikle ince esnek osteotomlar ile proksimalden gevşetilerek çıkarılmaya 

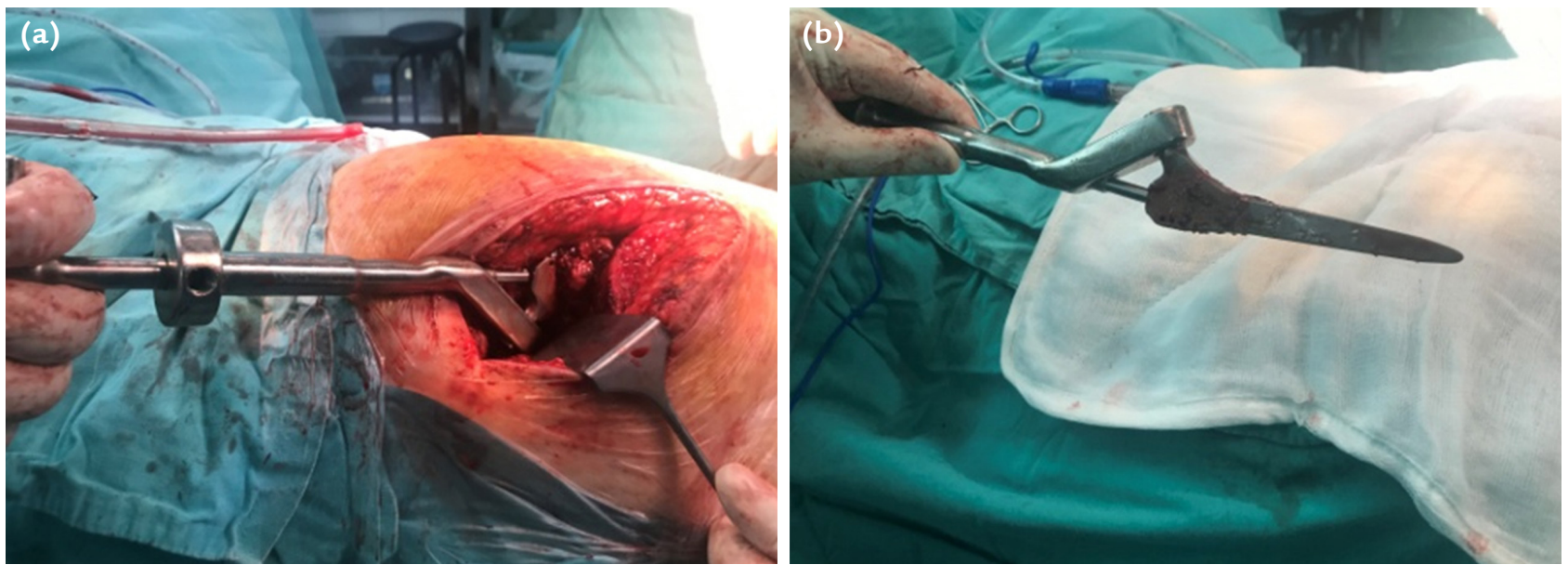

Şekil 4. a, b. Çıkartııı sistemin uygulanması (a) ve gevşek femoral komponentin çıkartılması (b).
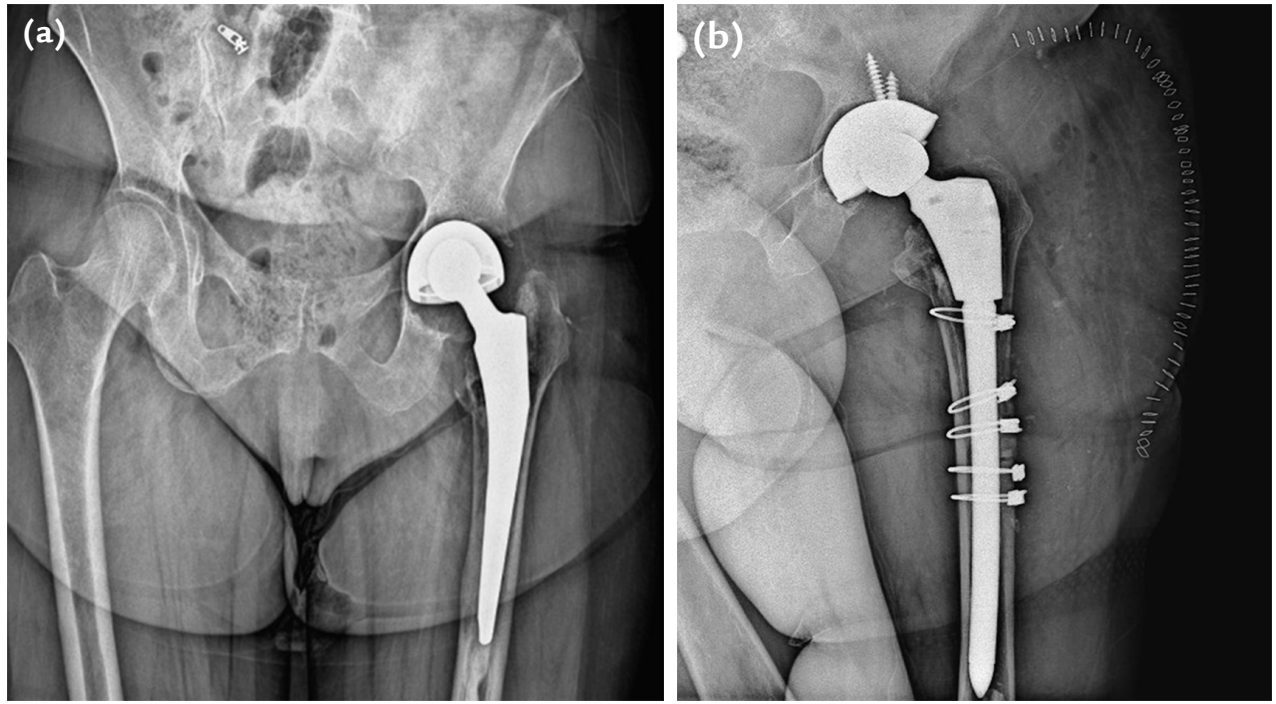

Şekil 5. a, b. Genişletilmiş trokanterik osteotomi (GTO) uygulanan bir olgunun revizyon öncesi (a) ve sonrasına (b) ait radyografik görüntüleri.

çalışılabilir; distal kısım için bu osteotomlar tehlikeli olabilir. Komponent bu şekilde çıkartılamazsa diğer alternatif yöntemlere başvurulabilir. Bu yöntemlerden biri, femur diyafizine kortikal bir pencere açmaktır. Yeterli açılım sağlamayan bu yöntem, yüksek iyatrojenik kırık riski sebebiyle, daha az tercih edilmektedir. Rahat çıkmayan, sıkı oturmuş femoral stemlerde kemik kaybını en aza indirmek ve ameliyat dönemi kırı̆̆ı önlemek için GTO yöntemi daha çok önerilmektedir. Genişletilmiş trokanterik osteotomi tekniği, hem çimentolu hem de çimentosuz femoral komponentlerin çıkarılmasında kullanılmaktadır. ${ }^{[4,49-51]}$

Genişletilmiş trokanterik osteotomi tekniğinde, osteotomi büyük trokanterden femoral diyafizi sağlam noktaya kadar uzanmalıdır. Osteotomiden önce, femur diyafizine proflaktik serklaj kablo uygulanabilir. ${ }^{[51]}$
İyatrojenik kırık riskini azaltmak için, osteotomi planlanan kısma önceden drill ile porlar açılır. Osteotominin distal bölgesi ve linea asperanın hemen anterolateralindeki tüm posterior osteotomi uzantısı boyunca, çok sayıdaki bu küçük porlar testere ile birleştirilir. Anterior korteksi kırmak için, osteotomi boyunca posteriordan anteriora geniş osteotomlar ilerletilir. Osteotominin geniş̧liği, femur çevresinin lateral üçte biri kadar olmalıdır. ${ }^{[4,37,49-52]}$

Büyük özen gösterilerek osteotomi açılır ve fragmanın öne doğru yeri değiştirilerek medulla görünür hale getirilir. Bu esnada büyük trokanterin kırımamasına dikkat edilmelidir. Fragmanın ön kısmındaki kasların kemik ile bağlantısı bozulmamalıdır. İmplant, çimento, tıkaç vs. temizlenir. Yeni femoral stem kanala yerleştirildikten sonra, çoklu kablo ile osteotomi kapatıı (Şekil 5). ${ }^{[4,37,49-52]}$ 


\section{KAYNAKLAR}

1. Brown JM, Mistry JB, Cherian JJ, Elmallah RK, Chughtai M, Harwin SF, Mont MA. Femoral component revision of total hip arthroplasty. Orthopedics 2016 39(6):e1129-39. Crossref

2. Hooper G, Rothwell A, Stringer M, Frampton C. Revision following cemented and uncemented primary total hip replacement: a seven-year analysis from the New Zealand Joint Registry. J Bone Joint Surg Br 2009 91-B(4):451-8. Crossref

3. Cram P, Lu X, Callaghan JJ, Vaughan-Sarrazin MS, Cai X, Li Y. Long-term trends in hip arthroplasty use and volume. J Arthroplasty 2012 27(2):278-85.e2. Crossref

4. Paprosky WG, Weeden SH, Bowling Jr JW. Component removal in revision total hip arthroplasty. Clin Orthop Relat Res 2001;393:181-93. Crossref

5. Fontalis A, Epinette J-A, Thaler M, Zagra L, Khanduja V, Haddad FS. Adv Innov Total Hip Arthroplasty SICOT J 2021;7:26. Crossref

6. Chang J-D, Yoo J-H, Hur M, Lee S-S, Chung Y-K, Lee C-J. Revision total hip arthroplasty for pelvic osteolysis with wellfixed cementless cup. J Arthroplasty 2007 22(7):987-92. Crossref

7. Masri BA, Mitchell PA, Duncan CP. Removal of solidly fixed implants during revision hip and knee arthroplasty. J Am Acad Orthop Surg 2005;13(1):18-27. Crossref

8. Ekinci M, Bilgin Y, Sayar $Y$, Ergin ON, Salduz A, Akgul T, Ozturk I. The Survival of Well-Fixed Cementless Femoral Component After Isolated Acetabular Component Revision. Ind J Orthop 2020;54(6):885-91. Crossref

9. Casper DS, Kim GK, Restrepo C, Parvizi J, Rothman $\mathrm{RH}$. Primary total hip arthroplasty with an uncemented femoral component: five-to nine-year results. J Arthroplasty 2011;26(6):838-41. Crossref

10. Lakstein D, Backstein DJ, Safir O, Kosashvili Y, Gross AE. Modified trochanteric slide for complex hip arthroplasty: clinical outcomes and complication rates. J Arthroplasty 2010;25(3):363-8. Crossref

11. Alberton GM, High WA, Morrey BF. Dislocation after revision total hip arthroplasty: an analysis of risk factors and treatment options. J Bone Joint Surg Am 2002 84(10):178892. Crossref

12. Sporer SM, Paprosky WG. Revision total hip arthroplasty: the limits of fully coated stems. Clin Orthop Relat Res 2003;(417):203-9. Crossref

13. Berend KR, Lombardi Jr AV, Seng BE, Adams JB. Enhanced early outcomes with the anterior supine intermuscular approach in primary total hip arthroplasty. J Bone Joint Surg Am 2009;91(Supplement_6):107-20. Crossref

14. Restrepo C, Parvizi J, Pour AE, Hozack WJ. Prospective randomized study of two surgical approaches for total hip arthroplasty. J Arthroplasty 2010;25(5):671-9.e1. Crossref

15. Matta JM, Shahrdar C, Ferguson T. Single-incision anterior approach for total hip arthroplasty on an orthopaedic table. Clin Orthop Relat Res 2005;(441):115-24. Crossref

16. York PJ, Smarck CT, Judet T, Mauffrey C. Total hip arthroplasty via the anterior approach: tips and tricks for primary and revision surgery. Int Orthop 2016;40(10):2041-8. Crossref

17. Kerboull L. Selecting the surgical approach for revision total hip arthroplasty. Orthop Trauma Surg Res 2015;101(1):S171-8. Crossref

18. Bauer R, Kerschbaumer F, Poisel S, Oberthaler W. The transgluteal approach to the hip joint. Arch Orthop Trauma Surg 1979;95(1-2):47-9. Crossref
19. Hardinge $K$. The direct lateral approach to the hip. J Bone Joint Surg Br 1982;64(1):17-9. Crossref

20. Pai VS. A modified direct lateral approach in total hip arthroplasty. J Orthop Surg (Hong Kong) 2002;10(1):35-9. Crossref

21. O'Brien JJ, Burnett RSJ, McCalden RW, MacDonald SJ, Bourne $\mathrm{RB}$, Rorabeck $\mathrm{CH}$. Isolated liner exchange in revision total hip arthroplasty: clinical results using the direct lateral surgical approach. J Arthroplasty 2004;19(4):414-23. Crossref

22. MacDonald SJ, Cole C, Guerin J, Rorabeck CH, Bourne RB, McCalden RW. Extended trochanteric osteotomy via the direct lateral approach in revision hip arthroplasty. Clin Orthop Relat Res 2003;(417):210-6. Crossref

23. Herndon $C L$, Drummond $N$, Sarpong NO, Cooper $H J$, Shah RP, Geller JA. Direct anterior versus mini-anterolateral approach for primary total hip arthroplasty: early postoperative outcomes and complications. Arthroplasty 2020;6(2):257-61. Crossref

24. Mokhtar MA. Postero-posterolateral approach in total hip arthroplasty. Int Orthop 2020;44(12):2577-85. Crossref

25. Marcy GH, Fletcher RS. Modification of the posterolateral approach to the hip for insertion of femoral-head prosthesis. J Bone Joint Surg Am 1954;36(1):142-3. Crossref

26. Hedley AK, Hendren DH, Mead LP. A posterior approach to the hip joint with complete posterior capsular and muscular repair. J Arthroplasty 1990;5:S57-66. Crossref

27. Mehlman CT, Meiss L, DiPasquale TG. Hyphenated-history: the Kocher-Langenbeck surgical approach. J Orthop Trauma 2000;14(1):60-4. Crossref

28. Iorio R, Healy WL. Heterotopic ossification after hip and knee arthroplasty: risk factors, prevention, and treatment. J Am Acad Orthop Surg 2002;10(6):409-16. Crossref

29. Farrell CM, Springer BD, Haidukewych GJ, Morrey BF. Motor nerve palsy following primary total hip arthroplasty. J Bone Joint Surg Am 2005;87(12):2619-25. Crossref

30. Rasmussen TJ, Black DL, Bruce RP, Reckling FW. Efficacy of corticosomatosensory evoked potential monitoring in predicting and/or preventing sciatic nerve palsy during total hip arthroplasty. J Arthroplasty 1994 9(1):53-61. Crossref

31. Satcher RL, Noss RS, Yingling CD, Ressler J, Ries M. The use of motor-evoked potentials to monitor sciatic nerve status during revision total hip arthroplasty. J Arthroplasty 2003;18(3):329-32. Crossref

32. Pereles TR, Stuchin SA, Kastenbaum DM, Beric A, Lacagnino $\mathrm{G}$, Kabir H. Surgical maneuvers placing the sciatic nerve at risk during total hip arthroplasty as assessed by somatosensory evoked potential monitoring. J Arthroplasty 1996;11(4):43844. Crossref

33. Lachiewicz PF, Soileau E, Ellis J. Modular revision for recurrent dislocation of primary or revision total hip arthroplasty. J Arthroplasty 2004;19(4):424-9. Crossref

34. Park Y-S, Moon Y-W, Lim B-H, Shon M-S, Lim S-J. A comparative study of the posterolateral and anterolateral approaches for isolated acetabular revision. Arch Orthop Trauma Surg 2011;131(7):1021-6. Crossref

35. Suh KT, Roh HL, Moon KP, Shin JK, Lee JS. Posterior approach with posterior soft tissue repair in revision total hip arthroplasty. J Arthroplasty 2008;23(8):1197-203. Crossref

36. Hummel MT, Malkani AL, Yakkanti MR, Baker DL. Decreased dislocation after revision total hip arthroplasty using larger femoral head size and posterior capsular repair. J Arthroplasty 2009;24(6):73-6. Crossref 
37. Younger TI, Bradford MS, Magnus RE, Paprosky WG. Extended proximal femoral osteotomy: a new technique for femoral revision arthroplasty. J Arthroplasty 1995;10(3):32938. Crossref

38. Sundaram K, Siddiqi A, Kamath AF, Higuera-Rueda CA. Trochanteric osteotomy in revision total hip arthroplasty. EFORT Open Rev 2020;5(8):477-85. Crossref

39. Wronka KS, Gerard-Wilson M, Peel E, Rolfson O, Cnudde $\mathrm{PHJ}$. Extended trochanteric osteotomy: improving the access and reducing the risk in revision THA. EFORT Open Rev 2020;5(2):104-12. Crossref

40. Stevens J, Macpherson G, Howie C. Bone preserving techniques for explanting the well-fixed cemented acetabular component. J Orthop 2018;15(2):500-5. Crossref

41. Burgess AG, Howie CR. Removal of a well fixed cemented acetabular component using biomechanical principles. J Orthop 2017;14(2):302-7. Crossref

42. De Thomasson E, Mazel C, Gagna G, Guingand O. A simple technique to remove well-fixed, all-polyethylene cemented acetabular component in revision hip arthroplasty. J Arthroplasty 2001;16(4):538-40. Crossref

43. Daum WJ, Calhoun JH. Removal of the acetabular component minimizing destruction of the bone bed. J Arthroplasty 1988;3(4):379-80. Crossref

44. Pierson JL, Jasty M, Harris W. Techniques of extraction of well-fixed cemented and cementless implants in revision total hip arthroplasty. Orthop Rev 1993;22(8):904-16. https:// pubmed.ncbi.nlm.nih.gov/8265229/

45. Mitchell P, Masri B, Garbuz D, Greidanus N, Wilson D, Duncan C. Removal of well-fixed, cementless, acetabular components in revision hip arthroplasty. J Bone Joint Surg Br 2003;85-B(7):949-52. Crossref
46. Ceynowa M, Zerdzicki K, Klosowski $\mathrm{P}$, Zrodowski M, Pankowski R, Roclawski M, Mazurek T. The cement-bone bond is weaker than cement-cement bond in cement-incement revision arthroplasty. A comparative biomechanical study. Plos One 2021;16(2):e0246740. Crossref

47. Liddle A, Webb M, Clement N, Green S, Liddle J, German M, Holland J. Ultrasonic cement removal in cement-in-cement revision total hip arthroplasty: What is the effect on the final cement-in-cement bond? Bone Joint Res 2019;8(6):246-52. Crossref

48. Lieberman JR, Moeckel BH, Evans BG, Salvati EA, Ranawat CS. Cement-within-cement revision hip arthroplasty. J Bone Joint Surg Br 1993;75-B(6):869-71. Crossref

49. Archibeck MJ, Rosenberg AG, Berger RA, Silverton CD. Trochanteric osteotomy and fixation during total hip arthroplasty. J Am Acad Orthop Surg 2003;11(3):163-73. Crossref

50. Chen W-M, McAuley JP, Engh Jr CA, Hopper Jr RH, Engh CA. Extended slide trochanteric osteotomy for revision total hip arthroplasty. J Bone Joint Surg Am 2000;82(9):1215-9. Crossref

51. Binazzi R, Felli L, Vaccari V, Borelli P. Surgical treatment of unresolved Osgood-Schlatter lesion. Clin Orthop Relat Res 1993;(289):202-4. Crossref

52. Prudhon JL, Tardy N. Extended trochanteric osteotomy: comparison of 3 modes of fixation: metallic wires, cables, plate, about a series of 157 cases. SICOT J 2018;4:21. Crossref 